\title{
A Study of the Effects of Teaching Literature on Improving Students' Second Language Attitudes
}

\author{
Mohammad Khatib (Ph.D.) \\ Department of English Language and Literature, Allameh Tabataba'i University, Tehran, Iran \\ Hossein Askari, Ph.D. Student (Corresponding author) \\ Department of English Language and Literature, Allameh Tabataba'i University, Tehran, Iran \\ Tele: (+98) 9371226162 E-mail: haskari301@gmail.com
}

Received: 08-06- 2012

doi:10.7575/ijalel.v.1n.4p.37
Accepted: 10-07- 2012

Published: 01-09- 2012

\begin{abstract}
The study aimed to investigate if teaching simple (not simplified) literary texts in university classes as their General English course-book can affect students' attitudes toward their L2. In view of this, a study was designed and conducted at Safashahr Azad University. Sixty-one freshmen learners (studying English as their General English) participated in the study. Ten short stories were taught as the course content of the GE in the experimental class. Short stories ranged from 106 words to 2294 words. "A General English Course for University Students" (Birjandi and Jaberi, 2005) was taught in the control group. The results showed that using literature in English classes brings positive effects on students' L2 attitudes. Using authentic simple literary texts in GE classes seemed to create a learning environment in which students were willing to participate in class interactions, which helped learners form a more positive attitude towards English.
\end{abstract}

Keywords: Literature, Literary texts, General English, L2 attitudes

\section{Introduction and Background}

Since the attitudinal factors are deep within the students' minds and we do not have a holistic understanding of them, the role of these factors in L2 learning has been one of the major concerns of second or foreign language (L2) researchers. Accordingly, various studies conducted in the area of learners' attitudes aimed at identifying students' attitudes toward learning an L2. The majority of these studies focused on the students' perceptions of English as an L2 and their looks toward it.

Attitude is also recognized as an important concept to understand human behavior and is considered as a mental state that includes beliefs and feelings (Latchanna \& Dagnew, 2009). Beliefs are one of the essential points correlating with learning a second language (Ajzen, 1988). Students' beliefs can hinder their learning, if they are turning a negative view toward their ability to learn a new language (Lennartsson, 2008). Ellis also states that negative attitudes can impede learning a language (1994). But the good news is that students' negative attitudes can change into positive, leading in turn to positive results (Lennartsson, 2008). Holding positive attitudes towards learning a language is surly a good start for learning a language. As Kramsch (2006) indicates language learners are the whole persons with hearts, bodies, minds, backgrounds, etc., not only communicators and problem-solvers, and the whole is to be taken into considerations.

The term 'attitude' is defined by 'Longman's Dictionary of Contemporary English' as “a way of feeling or thinking about someone or something, especially, as this influences one's behavior". Language attitudes, however, are different from other general attitudes in the sense that they are specifically about language and speakers of the language. In fact the term language attitude, as it is applied by sociolinguists today, includes the outlook and stance towards speakers of a particular language as also a variety of behavior concerning language.

Lambert (1963b) proposed a "social psychological model" to put emphasis on the cognitive factors like language aptitudes and intelligence as well as affective factors such as attitudes and motivation. In the model, he states that degree of individuals' successful acquiring of a second language depends upon ethnocentric tendencies, attitudes towards the other community, orientation towards language learning and motivation. 
The relationship between students' background (cultural or the like) and the one added by a L2 culture often has an effect on students' attitudes toward the second language. That's why some researchers (e.g. Lambert, 1990) speak of two major types of bilingualism: 'additive' and 'subtractive'. In the former, the learners think they are adding something new to their repertoire by learning a new language, while nothing is taken away in return. In the latter, they think learning a new language threatens their prior knowledge. Successful language learners are considered to be in the former category. Of course, many other factors are involved as well.

It is generally accepted that knowing English language is a key to success in academic or professional life. A student's attitude toward learning the language is one of the important factors affecting success in learning English. Therefore, teachers and educators should consider attitudinal factors (as one of the factors) in designing English language courses or developing instructional contents (Hall, 2009).

Ellis (2000) mentions that positive attitudes towards the L2 and its speakers can be expected to enhance learning while negative attitudes impede it. There are ways to improve students' attitudes toward a second language.

A study carried out by Masgoret \& Gardner (2003), focusing on the relationship between second language achievement and five attitude/motivation variables, showed that the correlation between achievement and motivation is higher than that between achievement and integration, and but this correlation is somewhat lower than that between achievement and attitudes toward the learning situation. The importance of attitude in learning a second language is clearly demonstrated in the results of the research.

On the other hand, as it is known the primary purpose of the literature is not to convey information, rather to involve readers in direct experience. Accordingly, literature seems to have potentials to help the teacher run the class, as Maley (1989) believes that literature enjoys some qualities including universality, non-triviality, personal relevance, variety, economy, etc. and these features make literature a special source for teaching a second language. Though literature provides the basis for intensely interactive, content-based ESL classes, they have not reached the popularity they deserve in ESL classes (Gajdusek, 1988). This is while literature, through its potentials for communication and interaction, might be able to raise learners' motivation and attitudes. And this needs to be put into research.

When dealing with reading in a second language, motivational factors are important to consider. Literature can solve the problem of motivation and attitude for many learners, since it, by nature, is interesting and can motivate learners to go to the language (McKay, 1982). This is of course when we approach literature as a literary experience not merely for vocabulary and grammatical points (Bradford, 1968). Bradford holds that having literary experience is the key point in succeeding or failing to take literature in ESL classes. To do so, literature should be the source of immediate pleasure and satisfaction, students should not be overloaded with new vocabulary or grammatical points, and they are to discover what is there in that piece of literature by themselves.

The rationale for using Literature in classrooms are presented in the guiding principles for education reform outlined in the Senior Secondary Curriculum Guide (2007 in Curriculum Development Council and the Hong Kong Examinations and Assessment Authority, (2007) :

- It helps learners to build up a humanistic outlook on life.

- Representing the human situation through a creative use of language, literary or creative texts can offer learners much aesthetic, intellectual and emotional pleasure.

- The study of Literature in English has many practical aspects.

- It offers great opportunities for learners to promote creativity, critical and analytical skills, and their language proficiency.

- It expands their awareness of the culture of different places where English is used,

- Learners are prepared for further study or work, particularly in areas such as publishing and the media through the intellectual, aesthetic and emotional qualities, which learners develop through studying Literature in English.

Van (2009) believes studying literature in the EFL classroom is advantageous for a number of reasons:

- It supplies meaningful contexts;

- It engages a great deal of vocabulary, dialogues and prose;

- It calls for imagination and enhances creativity; 
- It promotes cultural awareness;

- It promotes critical thinking; and

- It stands to CLT principles.

Nasr (2001, in Bagherkazemi \& Alemi 2010), in reviewing the relevant literature, makes some points supporting literary use in EFL/ESL classes:

- It has the potential to consolidate the four language skills: reading, writing, speaking and listening.

- It requires learners to think out and put into practice special reading strategies to deal with the idiosyncratic characteristics of verse and prose.

- It broadens intellectual perspectives, and boosts cognitive maturation.

- It helps learners develop feelings for the language they are learning.

Ladousse-Porter (2001) claims that reading a literary text activates and enhances the reader's emotional intelligence (EQ).

Literature, through its great potency to raise learners' motivation and broaden their views toward the world, can change learners' views and expand them regarding the second language they are learning. This might be helpful for learners who do not like the language and give them fractions of opportunities to like the second language and accordingly go to it more enthusiastically. This study was an attempt to see if taking literature to ESL classes as their course books for their General English course can affect learners' attitudes toward the second language they are learning. There is no course book available in the market for general English which is composed of (simple) literary texts, while much has been said in this regard in the relevant literature. Accordingly the authors wanted to know if taking simple literary texts to general English classes can be considered as a kind of help to learners.

\section{The study}

This study aims to investigate the effect of teaching literature (simple, not simplified, authentic literary texts) on improving students' second language attitudes. It is intended to investigate if teaching literature in General English (GE) classes can make any differences in students' attitudes towards English as their second language.

\subsection{Participants}

Two intact classes were selected (at Safashahr Azad University) out of six General English classes based on Convenience Sampling. Sixty-one freshmen learners (studying English as their General English course) took part in the study in two classes: 1 and 2 (numbers were given to classes nominally). Thirty-two and twenty-nine students attended class 1 and 2 respectively. Participants were all students of other majors (rather than English Language), their ages ranged from 19 to 28 (according to Educational Dep. report), students of all ages (19-28) were present in both classes 1 and 2 . The classes were assigned as experimental and control groups by flipping a coin. So class 1 (32 participants) was considered as experimental group and class 2 (29 participants) as control group. All participants were at the same level of proficiency (based on the pre-test given).

\subsection{Method}

The classes met twice a week (each session one hour and half); in both sessions the teacher paid attention to reading comprehension, vocabulary and some grammatical points (if necessary).

In class 1 simple (not simplified) literary texts were taught as the content of their course book, and in class 2 a course book ("A General English Course for University Students", by Birjandi and Jaberi, 2005) written for General English course for ESL students) was taught which is considered as a non-literary course book

In class 1, 10 short stories were taught as the course content of the GE. The short stories were taken from "east of the web" site, according to their lengths. The site provides a range of short stories from half a page to 7 pages. The stories are intended as literature for children and young adults, but with a message for adults. The short stories' names were "The Wolf in Sheep's Clothing, The Fox and the Crow, The Miser, The Princess and the Pea, The Little Match-Seller, The Tidy Drawer, Mr. Sticky, King Grisly-Beard, Polly Helps a Friend, and The Red Shoes" ranging from 106 words to 2294 words.

To neutralize the problem of differences among cultures and in order to motivate the necessary patience and involvement (Gajdusek, 1988), the starting point for this study was the sense shared by Persian and English cultures: short stories "The Wolf in Sheep's Clothing", "The Fox and the Crow" and "The Miser" are shared 
between these two cultures and participants of this study felt more at home with them as the start (according to learners' reports).

Considering the significant textual features of literature, Gajdusek (1988) reveals a four level sequence for class work, based on which the framework for teaching short stories in the GE classes for this study was derived:

1. Pre-reading activities: essential background information and vocabulary

2. Factual in-class work: who, where, when and what (happens)

3. Analysis: aspects of structure, theme and style

4. Extending activities: in-class activities that extend the ideas or situations encountered in the text

In the level one, as reading theory encourages, learners were provided with background information to help ESL readers. However, it was tried not to supply a summary of the actions or a statement of the theme. As Gajdusek (1988) states, we have not "the right to diminish the pleasure of personal discovery" by giving students the detailed information on the theme or the plot. Some words were paid attention to, especially those which contain essential hints to the cultural and emotional context of the story and words that "proficient readers merely categorize". Words whose meanings could be derived from the context mostly were put to learners. In the same phase, some parts of the story was tried to be linked to students' lives.

In level two (the factual in-class work), it was time to let learners read and work with the text at home. Two techniques were used to encourage students to read the stories at home: they were asked to answer the questions raised in the pre-reading level, and the teacher (to make learners read) did not read the whole story in the class and did not provide a line by line explanation. Here the attention was given to point of view, characters, setting and actions. For some activities small groups were formed and they were asked to consult.

Level three (analysis), going through levels one and two, learners now were ready to ask "why" and to develop their attitudes toward the characters, values and situation of the stories,. Here learners were expected to go beyond the information presents in the stories. Students, in this phase, extended their understandings of the stories' plot, conflict and climax. The teacher here acts as a moderator, trying to direct the conversations to legitimate interpretations of the stories (usually more than one interpretation).

In the extending activities level (level 4), students were asked, for example, to give their own solutions to the problems in the stories, and it was said that students' writings were appreciated and most welcome, the teacher tried to urge learners to write a critical writing, rather than only be narrative, or to have some words on a special event or relation (e.g. the kind of relation between the girl and her father in "the little match seller") in the story.

In class 2, each session one lesson of the book (A General English Course for University Students by Birjandi and Jaberi, 2005) was taught to learners. It was tried that the class follows a specified route, as close to the procedures followed in class no 1, accordingly at first there was a warm up in each session, in order to familiarize learners with the text, then some general questions were raised and learners were referred to the text to find the answer (through a short period of silent reading), teacher tries to provide clues and encourage them to go on. Then the text was read loudly for sake of pronunciation, after that the text was elaborated (through students' participations), vocabularies were exemplified, and learners were asked to repeat the new words after learners learnt what they meant. After the lesson was elaborated learners were pushed to get involved with the text, through questions and making links between the text and their real lives. A summery was asked in the next stage; 5 minutes were given to students, in order to prepare and tell a summary of the lesson using their own words and sentences.

During the term some grammatical points were explained (e.g. passive and active voices, conditionals type 1 and 2, etc.), as well as some collocations, prepositions or the like. Each session, students had some minutes of discussion on the content of the lesson (they liked it or not, why, the problems in the text and possible solutions, and giving summaries, or their critical views, etc.) and at the end of the session they were asked to do the exercises for the next session. The next session started with students possible questions on the text (if any) and the exercises. Students were asked to write a summary of the lessons every second sessions; the writings were corrected back to learners.

\subsection{Instruments}

To conduct the study, a Michigan test was given to ensure homogeneity, at the beginning of the semester. It took about 80 minutes for students to answer the Michigan test. The results of the test showed that learners of both experimental and control groups were homogeneous.

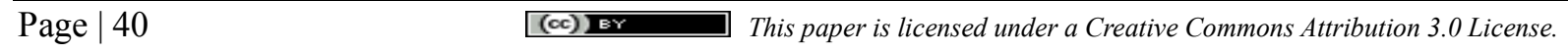


Since the study was going to investigate the effects of teaching literature in GE classes on the students' attitudes towards English as their second language, it was necessary to provide a basis for further comparison between learners' attitudes before and after receiving literature teaching. So FLAGS (Foreign Language Attitudes and Goals Survey) questionnaire (Eva Cid, Gisela Grañena, Elsa Tragant, 2009) was given to students of both classes at the beginning of the semester. The same questionnaire was also given to participants at the end of the same semester to find out if their attitudes have undergone any changes which could be attributed to the materials taught in the classes.

It took approximately about 30 minutes for each participant to answer the questionnaire. The statistical analysis of the questionnaires was conducted using SPSS 16.0 software.

FLAGS (Foreign Language Attitudes and Goals Survey) (Eva Cid, et.al. 2009), includes 59 items and it is divided into two sections. Section I includes 40 items (half of them negatively worded), 34 statements referring to attitudes and six negatively worded statements referring to goal orientations. Students were asked to show their level of agreement with the statements out of four options ('very much agree', 'moderately agree', 'slightly disagree' and 'totally disagree'). Section II included 19 positively worded goal orientations. Students were asked to show the level of importance they attached to the items, which were preceded by one of these two prompts 'I would like to learn English. . .'/I am interested in learning English. . . Students could choose among four options: 'very important', 'moderately important', 'not very important' and 'not important at all'.

\section{Results and Discussion}

The study intended to explore the effects of teaching literature in general English classes on improving students' second language attitudes. To this end, the same attitude questionnaire was given to the students both at the beginning and at the end of the semester to both experimental and control groups. The results showed that using literature in experimental class brings positive effects on students' second language attitudes. The results of hypothesis testing are described below.

H0: Teaching literature in General English classes will bring about the same results as teaching other types of texts in General English classes, regarding learners' second language attitudes.

To test the Hypothesis, the results of both attitude questionnaires as pre-test (at the beginning of the term) and post-test (at the end of the term) for both experimental and control groups were compared through paired sample t-test. The results of comparison between the pre and post-tests of experimental group are presented in table 1. And the results of comparison between pre and post-tests of control group appear in table 2 .

Table 1. Paired Samples Test; experimental group

\section{Paired Differences}

\begin{tabular}{|c|c|c|c|c|c|c|c|c|c|}
\hline & & \multirow[b]{2}{*}{ Mean } & \multicolumn{6}{|c|}{$\begin{array}{l}95 \% \text { Confidence } \\
\text { Interval of the } \\
\text { Difference }\end{array}$} & \multirow{2}{*}{$\begin{array}{c}\text { Sig. } \\
\text { (2-tailed) }\end{array}$} \\
\hline & & & $\begin{array}{l}\text { Sta. } \\
\text { Deviation }\end{array}$ & $\begin{array}{l}\text { Sta. Error } \\
\text { Mean }\end{array}$ & Lower & Upper & $\mathrm{t}$ & $\mathrm{df}$ & \\
\hline $\begin{array}{l}\text { Pair } \\
1\end{array}$ & $\begin{array}{l}\text { L2.attitude.pre - } \\
\text { L2.attitude.post }\end{array}$ & $\begin{array}{r}-31.18 \\
8\end{array}$ & 9.697 & 1.714 & -34.684 & -27.691 & $\begin{array}{r}-18.19 \\
4\end{array}$ & 31 & .000 \\
\hline
\end{tabular}

As shown in table 1, the sig. level .000 implies that the difference between pre and post-tests of the experimental class is significant at the level of $\mathrm{P}=0.01$. The negative mark in "mean" column indicates that students" marks at their post-tests were higher than those of their pre-tests. It means that there is a significant difference between the mean scores of the pre and post-tests of experimental group. In other words, using literature in general English experimental class helped learners to improve their second language attitudes significantly. 
International Journal of Applied Linguistics \& English Literature

ISSN 2200-3592 (Print), ISSN 2200-3452 (Online)

Vol. 1 No. 4; September 2012

Table 2. Paired Samples Test; control group

Paired Differences

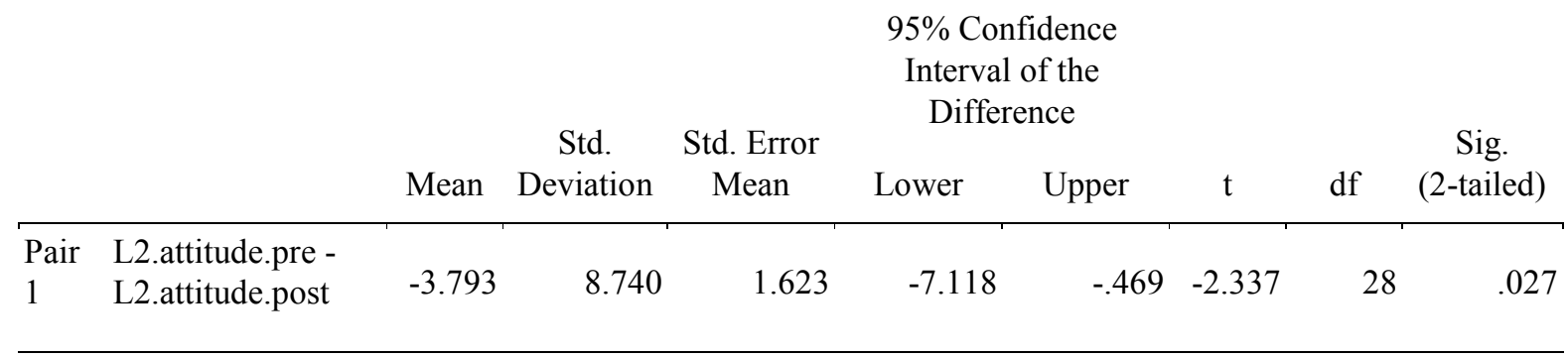

Table 2 shows the results for the comparison between pre and post-tests of control groups. As shown in the table, the significance level is 0.027 which is smaller than the assumed significance (0.05), meaning that the differences between the students' mean scores on pre-test questionnaire and the post-test one is significant. In other words, significant changes in students' attitudes happened at the end of the semester compared to the beginning of the semester.

Since after a semester of studying General English (literature in one class and a book for general English in the other), learners' attitudes changed significantly in both classes, we were to discover if the changes in both groups are the same. Accordingly, another computation is needed to find out if the differences between the experimental and control group in their pre- and post-tests are significant. To this end, two independent t-tests were run between pre-tests of the both experimental and control groups, and the post-tests of the experimental and control groups.

Table 3. Independent Samples Test between experimental and control groups for both pre- and post-test

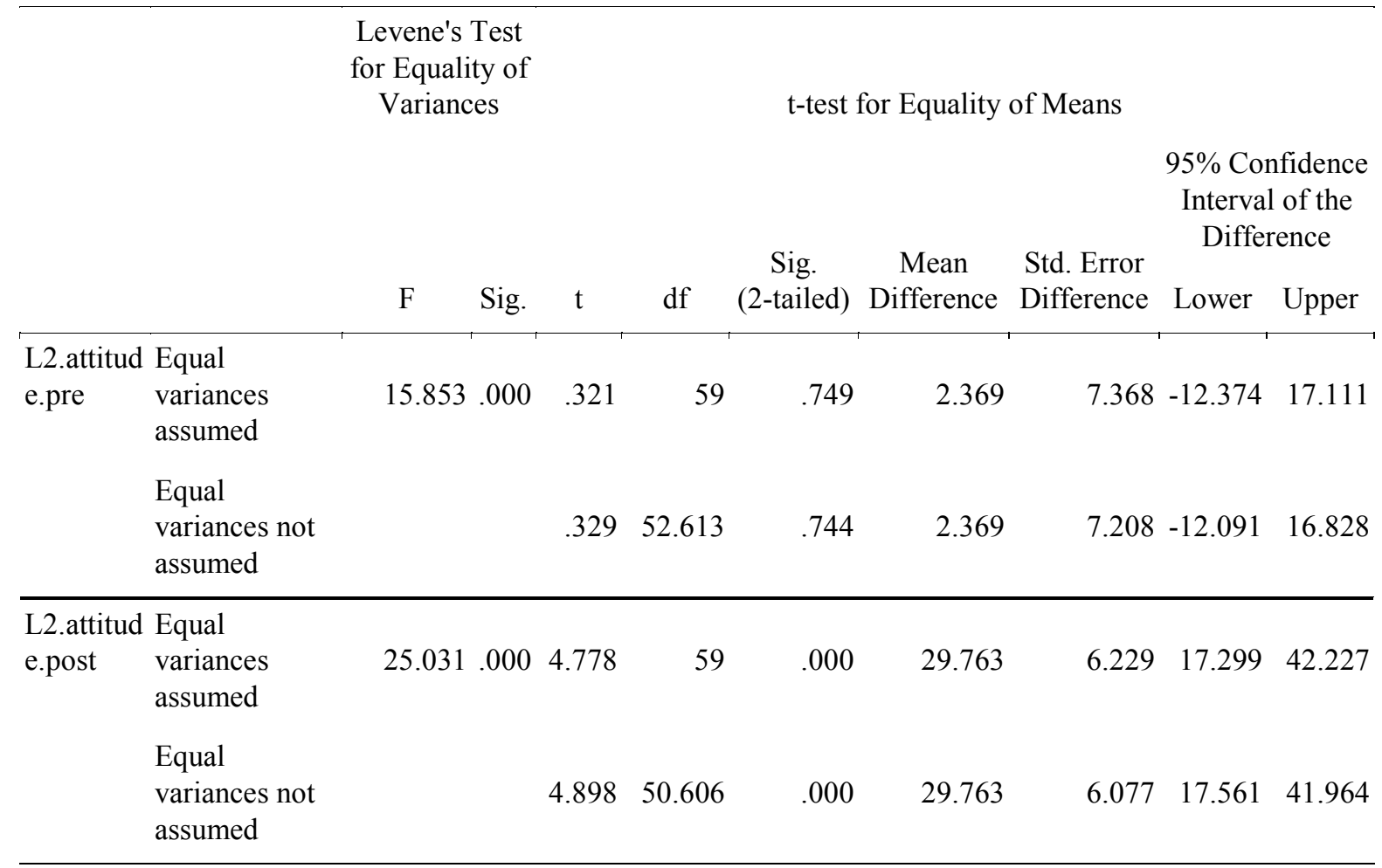

Table 3 pays attention to the comparisons of pre-test of experimental group with pre-test of control group on one hand and post-test of experimental group with post-test of control group on the other hand. It can be observed from the table that the significance value for pre-tests of both control and experimental groups is 0.000 which is 
much less than 0.05 , so we should refer to the second row of the same shelf which says "equal variances not assumed". The 0.744 (Sig. 2-tailed) says that the two groups can be considered as homogeneous regarding their attitudes towards the second language in their pre-tests.

The bottom shelf of the above table (3) shows a sig. of .000, since it is smaller than the assumed significance 0.05 , we are to go to the second row of the shelf meaning that "equal variances not assumed". The 2-tailed Sig. $(.000)$ reveals that the two groups (experimental and control) are no longer homogeneous in their post-tests, and that there is a significant difference between the two groups. As shown in the table (3), the mean difference between experimental and control groups is 29.763. This figure comes from the difference between the mean difference of experimental groups' pre and post-tests (table 1) which is 31.188 on one hand, and the mean difference of control group's pre and post-tests (table 2) which is 3.793 on the other hand. In other words it can be said that teaching literature in experimental class as their general English course book made a significant change in students' attitudes towards their second language, English.

The means of both pre- and post-tests for both experimental and control groups, their standard deviations, along with the number of participants for each group are presented in table 4 .

Table 4. Group Statistics

\begin{tabular}{|c|c|c|c|c|c|}
\hline & group & $\mathrm{N}$ & Mean & Std. Deviation & Std. Error Mean \\
\hline \multirow[t]{2}{*}{ L2.attitude.pre } & experimental & 32 & 141.44 & 34.098 & 6.028 \\
\hline & control & 29 & 139.07 & 21.280 & 3.952 \\
\hline \multirow[t]{2}{*}{ L2.attitude.post } & experimental & 32 & 172.62 & 29.345 & 5.188 \\
\hline & control & 29 & 142.86 & 17.041 & 3.165 \\
\hline
\end{tabular}

The study investigated whether teaching literature in general English classes can improve students' second language attitudes. Teaching literature in general English classes could (in this study) boost their L2 attitudes. The research results revealed that the students who went through literature instruction in their general English class showed to grow a significantly higher and more positive attitudes towards their second language (English). In addition, teaching literature helped learners in the experimental group attain a higher level of goal orientation in terms of learning a second language; this was inferred from the results of the questionnaire, since the questionnaire FLAGS paid attention to both Foreign Language Attitudes and Goals Survey.

Using literature in English classes is reported to be multi-dimensional; it can improve students' language proficiency, teach them some cultural points, help them have a deeper understanding of the language and context and many more (Maley, 1989; Mckay S., 1982; Preston W., 1982; Gajdusek L., 1988). Besides, literature, through its numerous merits, is capable of improving learners' abilities to see from different eyes, to experience real and authentic pieces of language, to tap learners' motivation and enthusiasm and to provide learners with more and more opportunities to enter the realms of unknown. On the other hand, learners' attitudes toward a second language or toward the people who use that language are a key to their success in learning a second language. One of the goals of English teachers in their classes is to enhance learners' second language attitudes in order to accelerate students' learning. To this end, teacher's characteristics are not the only things which matter, rather the material which are taken to the class are an important part of the story. Literature have been tried to be beneficial from different perspectives, and it proved, in this study, that literature was able to give rise to learners' attitudes toward their second language.

The typical education system favors not to approach literature as material for teaching a second language. This emanates from the idea that "teachers either consciously or unconsciously feel that literature is too 'hard' for ESL students" (Gajdusek, 1988). And the problem will be doubled when teachers come to this conclusion without testing literature potentials in real contexts i.e. their classes.

When using literature in general English classes, teachers are to remember that the material cannot be dealt with in the same way as they are doing with other types of texts, e.g. scientific texts. Learners are to first of all enjoy the text and discover what is there by their own (Gajdusek, 1988). The experience is to be shared with students 
and let them bring up their opinions and values. Moreover, literature encourages students to reflect on issues from multiple perspectives (Oster, 1989).

The application of literature in general English classes intends to create a comfortable English learning environment in which students are willing to participate in class interactions, and accept language as an alternative means of communication, next to their L1, which can give them a different experience in many regards, not only as something which is to be learnt. In order to let students have a pleasurable and different experience, simple literary texts can be taken to the class, and the teacher should prove to be supportive psychologically and emotionally, this all happen when learners are to experience a piece of language in the class which is true life.

As known, some learners are discouraged by their negative attitudes towards the second language they are learning. Using simple literary texts into general English classes can be a good way to kill two birds with one stone; on one hand learners' life experience can be improved which is a key to their personal and sometimes educational lives' success, and on the other hand, it can give rise to learners' second language attitudes which in its own turn is a powerful determinant of learners' success. A positive attitude can bring about higher motivation and openness to what learners are exposed to in or out of the class (Ajzen, 1988; Lennartsson, 2008; Ellis, 1994).

\section{Conclusion and Implications}

Second language research on using literature in ESLclasses has mostly paid attention to enhancing learning and skills development. In an attempt to the same direction the present study addressed the question of whether using simple (not simplified) literary tests in General English classes can affect learners' second language attitudes. To this end a study was designed and conducted at Safashahr Azad University; two out of six General English classes were sampled based on Convenience Sampling. 61 freshmen learners took part in the study in two classes. 32 and 29 students attended class 1 and 2 respectively. Participants were all students of other majors (rather than English Language), their ages ranged from 19 to 35 (according to Educational Dep. report). The classes were assigned as experimental and control groups by flipping a coin. So class 1 (32 participants) was considered as experimental group and class 2 (29 participants) as control group. In experimental group the course book was a pamphlet composed of 10 short stories, the short stories' length ranged from half a page to 7 pages. The control group experienced the book “A General English Course for University Students”(Birjandi and Jaberi, 2005). And this was the only difference between the two groups. FLAGS (Foreign Language Attitudes and Goals Survey) questionnaire (Eva Cid, Gisela Grañena, Elsa Tragant, 2009) was given to students of both classes at the beginning and at the end of the semester which provided information for statistical computations.

The statistical analysis procedures in this study showed a significant positive difference between the group (experimental) which had the simple literary texts as their course content, and the group (control) which did not have literary texts as their course content in their General English classes. Thus the null hypothesis saying "Teaching literature in General English classes will bring about the same results as teaching other types of texts in General English classes, regarding learners' second language attitudes." was rejected. And the study proved that (with the participants at hand) teaching simple literary texts in General English classes can significantly improve learners' second language attitudes.

Since, as appeared in the relevant literature, one of the obstructs which holds learners back on their ways to succeed learning a second language is students' attitudes towards the language they are to learn and the speakers of that language (Hall, 2009; Masgoret \& Gardner, 2003; and Ellis, 2000), teaching simple literary texts in General English classes can be used as a tool to improve learners attitudes in this regard. Teaching literature in General English classes is a bilateral activity resulting in learners' second language culture to improve (as said by many scholars like Bagherkazemi, M. \& Alemi, M., 2010; Sandra, 1982; Bradford, 1968), and in learners' second language attitudes to boost.

\section{References}

Ajzen, I. (1988). Attitudes, personality, and behavior. Chicago: Dorsey Press.

Bagherkazemi, M. \& Alemi, M. (2010). Literature in the Efl/Esl Classroom: Consensus and Controversy. LiBRI. Linguistic and Literary Broad Research and Innovation, 1(1).

Birjandi, P. and Jaberi, P. (2005). A General English Course for University Students. Shahidi Mahdavi Publication. 
International Journal of Applied Linguistics \& English Literature

ISSN 2200-3592 (Print), ISSN 2200-3452 (Online)

Vol. 1 No. 4; September 2012

Bradford, A. (1968). Reading Literature and Learning a Second Language. Language Learning, XVIII, (3).

Curriculum Development Council and the Hong Kong Examinations and Assessment Authority, (2007).

Literature in English: Curriculum and Assessment Guide (Secondary 4 - 6).

Ellis, R. (2000). The study of second Language Acquisition. Oxford/ New York: Oxford University Press.

Eva Cid, Gisela Gran ena, Elsa Tragant. (2009). Constructing and validating the foreign language attitudes and goals survey (FLAGS). System 37, 496-513.

Gajdusek Linda (1988). Toward wider use of literature in ESL: why and how. TESOL QUARTERLY, Vol. 22, No. 2.

Hall, S. (2009). Studies on attitudes towards learning English. [Online] Available:

http://www.ehow.com/way_5766640_studies-attitudes-towards-learning-english.html

Kramsch, C. (2006). From communicative competence to symbolic competence. The Modern Language Journal 90(2), 249-252.

Ladousse- Porter, G. (2001). Using literature in the language classroom: Whys and wherefores. English Teacher: An International Journal, 5(1), 27-36.

Lambert, W. (1963). Psychological approaches to the study of language. Modern Language Journal. 47, 51-62.

Lambert, W. (1990). Persistent issues in bilingualism. In B. Harley, P. Allen, J. Cummins \& M. Swain (eds), The development of second language proficiency. (pp. 201-218). Cambridge: Cambridge University Press.

Latchanna, G. \& Dagnew, A. (2009). Attitude of teachers towards the use of active learning methods. E-journal of All India Association for Educational Research, 21(1),

http://www.ejournal.aiaer.net/vol21109/12.\%20Latchana\%20\&\%20Dagnew.pdf

Lennartsson, F. (2008). Students' motivation and attitudes towards learning a second language:British and Swedish students' points of view. [Online] Available: http://urn.kb.se/resolve?urn=urn:nbn:se:vxu:diva-2571.

Maley, A. (1989). 'Down from the Pedestal: Literature as Resource.' in Brumfit, C., R. Carter, and R. Walker (Eds.) Literature and the Learner: Methodological Approaches ELT Documents 130 (pp.11-24). Modern English Publications in association with the British Council.

Masgoret, A. \& Gardner, R. (2003). Attitudes, motivation and second language learning: a Meta-analysis of studies conducted by Gardner and Associates. Language Learning. 53 (1), 123-164.

Mckay Sandra (1982). Literature in the ESL Classroom. TESOL QUARTERLY, 16(4).

Oster Judith (1989). Seeing with different eyes: another view of literature in the ESL classes. TESOL

QUARTERLY, 23(1).

Preston William (1982). Poetry ideas in teaching literature and writing to foreign students. TESOL

QUARTERLY, 16(4).

Van, T.T.M. (2009). The relevance of literary analysis to teaching literature in the EFL classroom. English

Teaching Forum, 3, 2-9. 